\title{
GENERALIZATION OF THE KANTOROVICH TYPE OPERATOR INEQUALITIES VIA GRAND FURUTA INEQUALITY
}

\author{
JADRANKA MIĆIĆ AND JOSIP PEČARIĆ
}

Abstract. In this note we show the characterization of the $\delta$-order by means of a generalized Kantorovich constant via Grand Furuta inequality, which is an extension result of that from $\mathrm{M}$. Fujii, E. Kamei and Y. Seo, Kantorovich type operator inequalities via grand Furuta inequality, Sci. Math., 3, (2000), 263-272. Among other, we show the following characterization of the $\delta$-order: Let $A, B$ be positive invertible operators on a Hilbert space $H$ satisfying $M I \geqslant A \geqslant$ $m I>0$ and $N I \geqslant B \geqslant n I>0$. Then the following statements are mutually equivalent for each $\delta \in[0,1]:$

$$
\begin{aligned}
& \text { (i) } A^{\delta} \geqslant B^{\delta}, \\
& \text { (ii) } K\left(n^{r}, N^{r}, 1+\frac{p-\delta}{r}, 1+\frac{q-\delta}{r}\right) A^{q} \geqslant B^{p} \text { for all } p>\delta, q>\delta \text { and } r>\delta, \\
& \text { (iii) } \bar{K}\left(m^{r}, M^{r}, 1+\frac{q-\delta}{r}, 1+\frac{p-\delta}{r}\right) A^{q} \geqslant B^{p} \text { for all } p>\delta, q>\delta \text { and } r>\delta,
\end{aligned}
$$

where the case $\delta=0$ means the chaotic order $\log A \geqslant \log B$.

Mathematics subject classification (2000): 47A63.

Furuta inequality.

Key words and phrases: operator order, chaotic order, Kantorovich inequality, Furuta inequality, grand

\section{REFERENCES}

[1] J. I. FUJII, Y. SEO, Characterizations of chaotic order associated with the Mond-Shisha difference, Math. Inequal. Appl., 5, (4) (2002), 725-734.

[2] M. FuJiI, M. HASHimoto, Y. SEO AND M. YANAGIDA, Characterizations of usual and chaotic order via Furuta and Kantorovich inequalities, Sci. Math., 3, (2000), 405-418.

[3] M. FUJI, E. KAMEI AND Y. SEO, Kantorovich type operator inequalities via grand Furuta inequality, Sci. Math., 3, (2000), 263-272.

[4] T. FurutA, $A \geqslant B \geqslant 0$ assures $\left(B^{r} A^{p} B^{r}\right)^{1 / q} \geqslant B^{(p+2 r) / q}$, for $r \geqslant 0, p \geqslant 0, q \geqslant 1$ with $(1+2 r) q \geqslant p+2 r$, Proc. Amer. Math. Soc., 101, (1987), 85-88.

[5] T. FURUTA, Extension of the Furuta inequality and Ando-Hiai log-majorization, Linear Algebra Appl., 219, (1995), 139-155.

[6] T. FURUTA, Operator inequalities associated with Hölder-McCarthy and Kantorovich inequalities, J. Inequal. Appl., 2, (1998), 137-148.

[7] T. FURUTA, M. GIGA, A complementary result of Kantorovich type order preserving inequalities by Mićić-Pečarić-Seo, Linear Algebra Appl., 369, (2003), 27-40.

[8] T. FuRUTA, Y. SEO, An application of generalized Furuta inequality to Kantorovich type inequalities, Sci. Math., 2, (1999), 393-399.

[9] M. HASHIMOTO, M. YANAGIDA, Further extensions of characterizations of chaotic order associated with Kantorovich type inequalities, Sci. Math., 3, (2000), 127-136.

[10] J. MićIĆ, J. PEČARIĆ AND Y. SEO, Function order of positive operators based on the Mond-Pečarić method, Linear Alg. Appl., 360, (2003), 15-34. 
[11] J. MićÍ́, J. PEČARIĆ, Characterizations of $\delta$-order associated with Kantorovich type operator inequalities, Sci. Math. Japon., 63, (2006), 149-155.

[12] Y. SEO, A characterization of operator order via grand Furuta inequality, J. Inequal. Appl., 6, (2001), 473-481.

[13] T. YAMAZAKI, M. YANAGIDA, Characterizations of chaotic order associated with Kantorovich inequality, Sci. Math., 2, (1999), 37-50. 